\title{
If NUCs protect SARS-CoV-2
}

\section{infection?}

\author{
Donika Todovichin ${ }^{1,2}$, Petar Trifonov ${ }^{2}$, Krasimir \\ Antonov ${ }^{1,2}$, Rosen Nikolov ${ }^{1,2}$, Irena Ivanova ${ }^{3}$
}

1. Clinic of Gastroenterology, UMHAT "St. Ivan Rilski", Sofia, Bulgaria

2. Department of Internal Medicine, Faculty of Medicine, Medical University -Sofia

3. Clinical Laboratory Department, UMHAT "St. Ivan Rilski", Sofia, Bulgaria

\begin{abstract}
We present data from our 4-month research for the effect of Tenofovir, Lamivudine and Entecavir on protection from SARS- CoV-2. We analyzed with rapid antibodies test the status of all patient with liver disease. The total number of examined patients is 478 . Their average age is $55,19 \pm 12,68$. Just 17 from $343(5 \%)$ of those on therapy have antibodies for SARS- CoV-2. 8 from the Tenofovir- treated patients were $\operatorname{lgM}(+)$ on a rapid test and 3- $\operatorname{lgG}(+)(5 \%)$. From those on therapy with Lamivudine, 5 were $\operatorname{lgM}(+)$ and $1-\lg G(+)(6,5 \%)$. No patients on Entecavir were positive for IgM or IgG antibodies for SARS-CoV-2.In contrast 14 from 135(10,3\%) from the patients without therapy have antibodies. We divided the patients by decades. In almost all decades the percentage of antibodies is two times lower in those on therapy than in those without.
\end{abstract}

Keywords: COVID-19, Chronic liver disease, HBV, treatment

\section{Introduction}

Coronaviruses are part of the subfamily Orthocoronavirinae, in the family Coronaviridae, order Nidovirales, and realm Riboviria. They are RNA-viruses. Transmission is usually via airborne droplets to the nasal mucosa. $80.9 \%$ of the patients infected with SARS- CoV-2, have mild symptoms such as acute, mild upper respiratory infection (common cold) and recover without therapy (2). The older and those with comorbidities can develop serious complications and that is the reason behind the attempts to find a cure for the 
disease.(1) By now the antiviral treatment for SARS-CoV-2 is not defined. Attempts are being made to find a cure from the available medications such as Remdesivir, Lopinavir/ritonavir, Interferons, Corticosteroids, Hydroxychloroquine, IL-6 inhibitor (3). Some of the discussed efforts are with Tenofovir, Lamivudine or Entecavir, which have been used for the treatment of Chronic Hepatitis B.

\section{Aim}

To analyse the frequency of anti- SARS- CoV-2 antibodies in Bulgarian patients with chronic liver disease.

\section{Materials \& Methods}

We analysed with rapid test the SARS-CoV-2 status of all patients with liver disease, who were monitored at the Clinic of Gastroenterology for the period from April 2020 to August 2020. The total number of examined patients is 478 . Their average age is $55,19 \pm 12,68.314(66 \%)$ of them are men and $164(34 \%)$ women. According to the antiviral treatment the patients were divided into two groups: the cohort of HBVpatients, treated with Tenofovir, Lamivudine or Entecavir (Group A, $n=343$ ), and a group of patients with various other chronic liver diseases without antiviral therapy (Group $B, n=135$ ). None of the monitored patients had a history for SARS-CoV-2.

\section{Results}

In this study we included $343 \mathrm{HBV}$ - patients, treated with nucleotide/nucleoside analogues (NUCs)- 221 were receiving Tenofovir(T), 93 on Lamivudine(L) and 29 on Entecavir(E). In this group $13(3,8 \%)$ patients were positive for SARS- CoV- 2 IgM antibody (8 T and $5 \mathrm{~L}$ ) and $4(1,2 \%)$ were positive for IgG antibodies on rapid test ( $3 \mathrm{~T}$ and $1 \mathrm{~L}$ ). No patients on Entecavir were positive for IgM or IgG antibodies for SARS-CoV2. In total, 17 from 343 patients (5\%) on antiviral were positive on rapid test for COVID- 19.

Group B consists of 135 patients. From them 9 were $\operatorname{IgM}(+)$ pos., 3 IgM (+) pos. and IgG (+) pos., and only 2 IgG (+) pos. for COVID-19. That makes 14 patients positive for any SARS-CoV-2 antibodies, or 10,3\%. In all 478 patients $25(5,2 \%)$ were IgM (+) pos. for COVID-19 and $9(1,9 \%)$ were IgG $(+)$ pos - Table 1.

\begin{tabular}{|l|c|c|c|}
\hline & \multicolumn{1}{|c|}{$\begin{array}{c}\text { Group A } \\
\mathrm{n}=343\end{array}$} & $\begin{array}{c}\text { Group B } \\
\mathrm{n}=135\end{array}$ & $\begin{array}{c}\text { Group A+B } \\
\mathrm{n}=478\end{array}$ \\
\hline Pos (+) IgM & $\begin{array}{c}\mathrm{n}=13(3,8 \%) \\
\text { 8 Tenofovir } \\
5 \text { Lamivudine }\end{array}$ & $\mathrm{n}=12(8,9 \%)$ & $\mathrm{n}=25(5,2 \%)$ \\
\hline Pos (+) IgG & $\begin{array}{c}\mathrm{n}=4(1,2 \%) \\
\text { 3 Tenofovir } \\
1 \text { Lamivudine }\end{array}$ & $\mathrm{n}=5(3,7 \%)$ & $\mathrm{n}=9(1,9 \%)$ \\
\hline Neg. IgM+ IgG & $\mathrm{n}=326(95 \%)$ & $\mathrm{n}=118(87,4)$ & $\mathrm{n}=444(93 \%)$ \\
\hline
\end{tabular}

Table 1: Distribution by SARS-CoV-2 antibody status

We divided the patients by decades and presented them in the table below. We found that the percentage of antibodies in patients from Group A in all age groups is two times lower than in those in Group B. Therefore, we can say that, regardless of age, in patients on therapy, there is a factor that prevents the virus 
from entering the body of patients. The difference is in decades 20-29 years and 70-79. In the decade 2029 the \% of patients positive for antibodies in Group B is $0 \%$. It may be due to the small number of Group $B$ patients in this range - 4 patients. In the decade 70-79 the \% positive patients from Group $A$ is higher than the Group B. It may be due the fact, that all the positive patients from Group A (3 patients) have cirrhosis, arterial hypertension and one of the four patients have chronic lymphocytic leukemia and is on therapy with Chlorambucil. These comorbidities may affect the susceptibility from SARS-CoV-2.

\begin{tabular}{|c|c|c|c|c|c|c|}
\hline Age & Total & $\begin{array}{c}\text { Total } \\
\text { positive }\end{array}$ & $\begin{array}{c}\text { NUC- HBV } \\
\text { total }\end{array}$ & $\begin{array}{c}\text { NUC- HBV } \\
\text { positive }\end{array}$ & $\begin{array}{c}\text { No NUC } \\
\text { total }\end{array}$ & $\begin{array}{c}\text { No NUC } \\
\text { positive }\end{array}$ \\
\hline $20-29$ & 10 & $1(1 \%)$ & 6 & $1(16,7 \%)$ & 4 & $0(0 \%)$ \\
\hline $30-39$ & 52 & $2(3,8 \%)$ & 37 & $0(0 \%)$ & 15 & $2(13,3 \%)$ \\
\hline $40-49$ & 100 & $5(5 \%)$ & 75 & $2(2,7 \%)$ & 25 & $3(12 \%)$ \\
\hline $50-59$ & 146 & $10(8,9 \%)$ & 82 & $6(7,3 \%)$ & 30 & $4(13,3 \%)$ \\
\hline $60-69$ & 58 & $7(4,8 \%)$ & 106 & $3(2,8 \%)$ & 40 & $4(10 \%)$ \\
\hline$>70$ & 32 & $7(12 \%)$ & 37 & $4(11 \%)$ & 21 & $3(14,3 \%)$ \\
\hline
\end{tabular}

Table 2: Percent of Patients with Antibodies divided by decades

\section{Discussion}

We found a frequency of $5 \%$ for patients with Chronic Hepatitis B on therapy, which corresponds to the PCR frequency for the country (4\%). Because the SARS-CoV-2 - PCR- frequency in Bulgaria is 4\%, it is possible that this $10 \%$ IgM or IgG positive patients with various other chronic liver diseases reflect the real rate of the infection in the population. It is expected, that the frequency of positive patients is higher with the rapid antibodies test, because it includes bigger time interval, asymptomatic patients, excluding technical error, when taking the sample. The total frequency is about $7 \%$. It gives the impression, that the patients on NUCs therapy have two times lower frequency from the other group. That is why we could say, that there is indeed a factor, which lowers the risk from infection from SARS-CoV-2.

After a randomized epidemiological study of antibodies in Plovdiv (4), in which 800 people took part, it became clear that the incidence of antibodies is $2 \%$. Until August 2020, the frequency of positive PCR tests in Bulgaria is $4.5 \%$. After reference, the rate of PCR positive tests in Greece is $0,8 \%$, in Serbia, it is $4 \%$, in North Macedonia - 11\%, in Romania - 4,4\%.

Following a literature review, we found an article called "Incidence and Severity of COVID-19 in HIV Positive Persons Receiving Antiretroviral Therapy" from Annals of Internal Medicine (3), describing the incidence of HIV-positive patients receiving TDF / FTC. Of 77590 HIV-positive persons receiving antiretroviral therapy, 236 were diagnosed with SARS-CoV-2, 151 were hospitalized, 15 were admitted to the ICU, and 20 died. The risk for SARS-CoV-2 hospitalization rate was 10.5 (Cl, 5.6 to 17.9) among those receiving TDF/FTC. These HIV-positive patients have a lower risk for SARS-CoV-2 and related hospitalization than those receiving other therapies. No patient receiving TDF/FTC was admitted to the ICU or died.

In our study, we observed that Tenofovir patients, who were more numerous, had a lower incidence rate. From this we can conclude that Tenofovir therapy has the greatest effect in the prevention of SARS-CoV-2. 
No morbidity was observed with Entecavir, but this was also due to the smaller number of patients enrolled in the study.

\section{Conclusion}

We observe that until now, there is a significant difference in morbidity between patients with chronic liver disease with and without NUCs therapy. As therapy for SARS-CoV-2 with virustaticsis being discussed, we speculate that treatment with Tenofovir, Lamivudine and Entecavir could offer relative prevention. Further investigation is needed.

\section{References}

1. Baron S, editor. Medical Microbiology. 4th edition. Chapter 60, 2010, 342-348

2. The Novel Coronavirus Pneumonia Emergency Response Epidemiology Team. ital Surveillances: The Epidemiological Characteristics of an Outbreak of 2019 Novel Coronavirus Diseases (COVID-19) China, 2020. China CDC Weekly 2020, 2(8): 113-122

3. Yang Songa,, Min Zhang, Ling Yinc, Kunkun Wang d, YiyiZhoue, MiZhouf, Yun Lug. COVID-19 treatment: close to a cure? A rapid review of pharmacotherapies for the novel coronavirus (SARS-CoV2). International Journal of Antimicrobial Agents Volume 56, Issue 2, August 2020, 106080

4. Interview with associate professor Kunchev about a randomised epidemiological study of antibodies in Plovdiv. https://news.bg/health/okolo-2-ot-balgarite-sa-se-sreshtnali-s-koronavirusa.html 5. Julia del Amo, MD, PhD, Rosa Polo, MD, PhD, Santiago Moreno, MD, PhD, Asunción Díaz, MD, PhD, Esteban Martínez, MD, PhD, José Ramón Arribas, MD, PhD, InmaJarrín, PhD, Miguel A. Hernán, MD, DrPH, and for The Spanish HIVICOVID-19 Collaboration. Incidence and Severity of COVID-19 in HIVPositive Persons Receiving Antiretroviral Therapy. Annals of Internal Medicine. 26 Jun 2020

\section{Corresponding author:}

Donika Todovichin

Clinic of Gastroenterology,

UMHAT "St. Ivan Rilski", Sofia, Bulgaria

Tel: +359896105652 